\title{
Infection-provoked psoriasis: Induced or aggravated (Review)
}

\author{
YAN TENG ${ }^{1 *}$, WENQING XIE ${ }^{2 *}$, XIAOHUA TAO $^{1}$, NA LIU $^{3}$, YONG YU $^{1}$, \\ YOUMING HUANG $^{1}$, DANFENG XU ${ }^{1}$ and YIBIN FAN ${ }^{1}$
}

\begin{abstract}
${ }^{1}$ Department of Dermatology, Zhejiang Provincial People's Hospital, People's Hospital of Hangzhou Medical College, Hangzhou, Zhejiang 310014; ${ }^{2}$ Department of Orthopaedics, Xiangya Hospital, Central South University, Changsha, Hunan 410008; ${ }^{3}$ Department of Dermatology, Bengbu Medical College, Bengbu, Anhui 233000, P.R. China
\end{abstract}

Received November 14, 2020; Accepted February 22, 2021

DOI: $10.3892 /$ etm.2021.9999

\begin{abstract}
Psoriasis is a common chronic, immune-mediated, inflammatory skin disorder, with a reported prevalence of 0.0-2.1\% among children and 0.91-8.50\% among adults, worldwide. Psoriasis is induced by several environmental factors, including infection, alcohol consumption, drugs, trauma, acute withdrawal of systemic or potent topical corticosteroids, body mass index and endocrine disorders. Increasing evidence suggest that a variety of microorganisms play key roles in the induction and exacerbation of psoriasis. Pathogens, such as streptococci and staphylococci are considered causal factors, presumably via superantigen activation of skin-seeking $\mathrm{T}$ cells. In addition, fungal pathogens, such as Candida and Malassezia, and viral agents, such as human immunodeficiency virus, hepatitis $\mathrm{C}$ virus infection and human papillomavirus, are also closely associated with psoriasis. Recently, several types of pathogens, such as Helicobacter pylori infection, Zika virus and scabies, have been reported to potentially trigger psoriasis. The present review discusses the underlying molecular mechanisms by which these infections influence psoriasis to provide a better understanding of the pathogenesis of psoriasis.
\end{abstract}

\section{Contents}

1. Introduction

2. Bacteria

3. Other bacterial agents

4. Fungi

5. Viruses

Correspondence to: Dr Yibin Fan, Department of Dermatology, Zhejiang Provincial People's Hospital, People's Hospital of Hangzhou Medical College, 158 Shangtang Road, Hangzhou, Zhejiang 310014, P.R. China

E-mail: frankgets@sina.com

${ }^{*}$ Contributed equally

Key words: psoriasis, microorganisms, bacteria, fungi, viruses
6. Other viruses

7. Other microorganisms

8. Conclusions

\section{Introduction}

Psoriasis is one of the most common inflammatory skin diseases and is considered to have several causal agents, including infection, alcohol consumption, drugs, trauma, acute withdrawal of systemic or potent topical corticosteroids, body mass index and endocrine disorders (1). It is recognized that certain species of bacteria, such as, streptococci and staphylococci, are associated with the induction and aggravation of psoriasis (2). However, the specific mechanisms are constantly being updated. In recent years, pathogens, including the bacterial species Helicobacter pylori, the fungi species Malassezia and Candida, viruses [human immunodeficiency virus (HIV), human papillomavirus (HPV) and hepatitis $\mathrm{C}$ virus infection (HCV)] and the Sarcoptidae species of mites (Table I) are considered to be associated with the occurrence and development of psoriasis (3). The present review aims to discuss all the possible pathogens reported associated with the onset or exacerbation of psoriasis, along with their potential and molecular mechanisms. In conclusion, information on the current understanding of the role and therapeutic targets of the infection during the onset and acute exacerbation of psoriasis is provided.

\section{Bacteria}

Streptococci. In the first report published 50 years ago, two thirds of patients with guttate psoriasis (GP) had an acute sore throat 1-2 weeks prior to the outbreak, and serological evidence of a preceding streptococcal infection (4). $\beta$-haemolytic streptococcal throat infection is associated with the onset and acute exacerbation of psoriasis (5). In a prospective study, patients with psoriasis suffered from a sore throat 10 times more than household controls (6). Streptococcus infection stimulates $\mathrm{T}$ cell proliferation through bacterial superantigens, without prior intracellular processing by antigen-presenting cells (7). Infiltrating $\mathrm{T}$ cells, which subsequently induce psoriatic skin lesions, derive from tonsils where streptococcal infection promotes a skin-homing phenotype, 
in which streptococcal and skin-specific epitopes function through molecular mimicry (8).

The human cathelicidin interleukin (IL)-37 peptide, a multifunctional regulator of components of the innate immune response, is overexpressed in patients with psoriasis (9). Following induction of streptococcal infection, monocytes expressing the surface markers CD14 and CD16 are usually activated in patients with GP. Peptidoglycan (PGN) is a major component of the cell wall of Streptococcus, and an increasing number of PGN-containing cells have been detected in psoriatic lesions (10). Qian et al (11) assessed the function of human IL-37 in the activity and differentiation of PGN-induced monocytes and subsequently investigated its association with GP. The results demonstrated that the levels of CD14 ${ }^{+}$ and $\mathrm{CD}_{16}{ }^{+}$monocytes, circulating IL-37, the soluble form of triggering receptor expressed on myeloid cells (sTREM-1), and anti-streptolysi $\mathrm{O}$ are significantly higher in patients with GP compared with healthy controls. In addition, the percentages of $\mathrm{CD}_{14}{ }^{+}$and $\mathrm{CD}^{+} 6^{+}$monocytes are positively correlated with serum sTREM-1 levels and Psoriasis Area and Severity Index (PASI) scores (12). Therefore, the authors concluded that IL-37 plays an important role in psoriasis via synergistic action with PGN to direct the polarization and differentiation of monocytes into a proinflammatory phenotype $(13,14)$. In addition, co-culture of psoriatic skin lymphocyte-associated antigen $\left(\mathrm{CLA}^{+}\right) \mathrm{T}$ cells and lesional epidermal cells revealed that IL-17A is the primary inducer of $\mathrm{ZC} 3 \mathrm{H} 12 \mathrm{~A}$ expression in keratinocytes treated with the supernatant derived from Streptococcus pyogenes-activated psoriatic precursor lesions (15).

A systematic review published in 2001 reported no satisfactory evidence of the efficacy of antibiotics in patients with chronic plaque psoriasis or acute GP, mainly due to the lack of satisfactory results compared with the placebo (16). A new and updated Cochrane review published in 2019 described the association between treatment with anti-streptococcal agents for chronic plaque psoriasis or GP (17). However, both the efficacy and safety of anti-streptococcal interventions remain unclear. These trials present a high risk of bias, only include a small number of unrepresentative participants and report limited measurements on the outcomes of interest. These studies failed to investigate the effects of streptococcal infection, and a key intervention (amoxicillin) was not assessed. Thus, further studies are required to assess the efficacy and tolerance of penicillin $\mathrm{V}$ or amoxicillin among both children and young adults with GP.

Several case series have recommended treatment with tonsillectomy for selected patients with GP and pustular psoriasis $(18,19)$. The results of a randomized controlled trial demonstrated that tonsillectomy is an important alternative to the current treatment of psoriasis for a selected group of patients, which provides long-lasting improvements (20). However, several studies with long-term follow-up are warranted to accurately determine the benefits of tonsillectomy in psoriasis $(20,21)$. In addition to the association between streptococcal infection of the throat and psoriasis, other case reports of GP in children with perianal streptococcal disease have been published (22-24). A dental focal infection may be an important causative or exacerbating factor for pustulosis palmaris et plantaris (PPP), and dental examinations along with tonsillar examinations, are recommended prior to treatment for PPP (25).

Staphylococci. In a systematic review, patients with psoriasis were 4-5 times more likely to be colonized by Staphylococcus aureus (S. aureus) on the skin and $60 \%$ more likely to be colonized in the nasal cavity compared with healthy controls [relative risk and 95\% confidence interval (CI), skin: 5.54 (3.21-9.57); nares: 1.60 (1.11-2.32)] (26). In addition, $S$. aureus isolates secrete more than one staphylococcal enterotoxin, including staphylococcal enterotoxins A, B, C and D (SEA, SEB, SEC and SED), and toxic shock syndrome toxin-1 (27). In another study, S. aureus isolated from patients with psoriasis secreted high levels of staphylococcal enterotoxin. Notably, the PASI scores of these patients were significantly higher compared with toxin negative $S$. aureus isolates (28). Göçmen et al (29) reported that both $S$. aureus colonization and the presence of toxin positive and agr genes may be critical for disease activity in patients with psoriasis. Compared with patients with atopic dermatitis (AD) or lichen planus, a greater inflammatory response was induced in patients with psoriasis following the topical application of staphylococcal toxins to tape-stripped, clinically uninvolved skin (30). Moriwaki et al (31) demonstrated that SLURPI participates in the pathophysiology of psoriasis by inhibiting the growth of $S$. aureus. Furthermore, T cells activated by S. aureus have been cultured from skin lesions of individuals with psoriasis. Unlike the total count of PGN-containing macrophages, the number of macrophages carrying $S$. aureus-specific PGN in these skin lesions is limited, suggesting that $\mathrm{T}$ cells specific to PGN from $S$. aureus may not participate in the pathogenesis of the disease (32).

Helicobacter pylori (H. pylori). H. pylori, a microaerophilic gram-negative bacterium, naturally colonizes the human gastric mucosa (33). Considered a global health problem, the incidence rate of $H$. pylori infection is up to $80-90 \%$ in some developing countries (34). Recently, several studies have reported an association between certain skin diseases and H. pylori infection, including AD, chronic spontaneous urticaria (35), rosacea (36), alopecia areata (35) and psoriasis, which may provide novel therapeutic strategies for these skin diseases. Notably, a recent systematic review reported that $H$. pylori infection is associated with the pathogenesis of psoriasis as these patients have higher PASI scores (37). The function of $H$. pylori infection in the pathogenesis of extradigestive manifestations is attributed to the systemic effect of the local inflammation caused by the bacterium (38). The bacterium colonizes the gastric mucosa and subsequently releases several cytotoxic substances to induce an inflammatory response (39). Thus, gastric infection with $H$. pylori may induce systemic effects that include increased permeability of the gastric mucosa to food antigens, immune regulation, autoimmune mechanisms and damage to vascular integrity (40). Researchers have proposed that the diversity of $H$. pylori immunopathogenesis may result from an imbalance in Th1 and Th2 responses (41). The enterotoxin secreted by $H$. pylori binds to the $\mathrm{T}$ cell receptor and induces the expression of the $\mathrm{T}$ cell skin homing receptor and skin lymphocyte antigen, which results in the occurrence of $T$ cell superantigen $(42,43)$. 
Table I. List of pathogens associated with the onset or exacerbation of psoriasis.

\begin{tabular}{l} 
Bacterium \\
Streptococci \\
Staphylococci \\
Helicobacter pylori \\
Porphyromonas gingivalis \\
Chlamydiae \\
Fungi \\
Candida \\
Malassezia \\
Viruses \\
HIV \\
HPV \\
HCV \\
Human herpesvirus \\
Coxsackie B \\
Chikungunya \\
Zika virus \\
Human parvovirus B19 \\
COVID-19 \\
Other \\
Sarcoptidae \\
\hline
\end{tabular}

HIV, human immunodeficiency virus; HPV, human papillomavirus; $\mathrm{HCV}$, hepatitis $\mathrm{C}$ virus.

\section{Other bacterial agents}

Periodontitis is a type of chronic gingivitis caused by an excessive inflammatory response to microbial colonies in dental plaques (44). It affects approximately one third of adults $>30$ years and approximately half of adults $>50$ years (45). Recently, the association between periodontitis and immune-mediated inflammatory diseases has attracted great interest (46). It is speculated that bacterial colonization in the oral cavity triggers an overactive immune response in susceptible hosts, causing a permanent inflammatory process associated with autoimmune disease $(47,48)$. This association has been extensively investigated in rheumatoid arthritis (RA), in which patients with periodontitis are 2-8 times more likely to have RA than patients without periodontitis (49).

A systematic review demonstrated that the risk of psoriasis is significantly higher among patients with periodontitis (50). The causative agent is speculated to be Porphyromonas gingivalis, a common gram-negative anaerobic periodontal pathogen, due to its unique ability to produce peptidyl arginine deiminase, the major enzyme that promotes the post-translational citrullination of peptides (51). Excessive levels of citrullinated peptides subsequently induce the production of anti-citrullinated peptide antibody (ACPA), a critical autoantibody involved in the pathogenesis of inflammatory diseases, such as RA synovitis (52). However, excessive citrullination of peptides is unlikely to increase the risk of psoriasis, as ACPA plays no role in the pathogenesis of this inflammatory skin disease (53). An informative analysis would be to determine whether patients with psoriasis and periodontitis have a risk of developing psoriatic arthritis compared with the general population with psoriasis (54). Although the exact molecular mechanism underlying the increased risk of psoriasis among patients with periodontitis remains unclear, several potential explanations have been proposed. First, it is likely to be associated with a common pathology between psoriasis and periodontitis, as an exaggerated immune response to the presence of a microbiome on the epithelial surface is observed in both cases, which may indicate a common genetic susceptibility that modulates dendritic cell activity and Toll-like receptor expression (55). Another explanation is that the bacteria and their products involved in periodontal infection induce the activation of Th17 cells and increase IL-17 expression (54). However, further studies are required to accurately determine the molecular mechanisms underlying this risk $(50,56,57)$.

Chlamydiae is a type of intracellular microorganism that tends to elicit persistent infection and may be the cause of neoplastic changes in host cells (58). Several studies performed over the last 5 years have reported a close association between Chlamydophila psittaci $(\mathrm{CP})$ and ocular adnexal malignant lymphomas, Waldeyer ring lymphomas and cutaneous diffuse large B-cell lymphomas $(59,60)$. Fabris et al (61) investigated the association between a subclinical $C p$ infection and autoimmune diseases, such as inflammatory polyarthritis. In the study, patients with seronegative polyarthritis, followed by psoriatic arthritis, had a higher prevalence of $C p$ infections. Subsequently, Stinco et al (62) reported that $17 \%(11 / 64)$ of patients with psoriasis had a subclinical $C p$ infection, while only $0.4 \%(1 / 225)$ of the healthy control group had a subclinical $C p$ infection. Chlamydiae is known to contribute to a strong immunogenic response that triggers several diseases (63). Similarly, the subclinical $C p$ infection is speculated to provide a basis for the staging of psoriasis by mimicking the host epitope, and its mechanism involves the function of bacterial superantigens (62).

\section{Fungi}

Candida. Candida spp. have been isolated from $15 \%$ of skin specimens from patients with psoriasis compared with just $4 \%$ of specimens from healthy controls $(\mathrm{P}=0.045)$, and in $60 \%$ of oral specimens from patients compared with $20 \%$ of specimens from healthy controls $(\mathrm{P}<0.01)(64)$. Notably, patients with psoriasis have lower levels of serum IgM, IgA and $\operatorname{IgG}$ against Candida albicans (C. albicans) compared with controls, suggesting that psoriasis may be associated with a decreased humoral immune reaction to Candida (64). Candida spp. may aggravate psoriasis by secreting toxins, and the presence of $C$. albicans in the gut has been speculated to induce the formation of superantigens, contributing to nonspecific T-cell activation and cytokine production, thereby triggering the psoriatic process (65). In addition, a previous study demonstrated that the outcome of over half of the 50 patients with psoriasis improved following treatments with oral nystatin (66).

Malassezia. Malassezia spp. are considered external triggers that induce the pathogenic features of psoriasis (67). Patch 
testing was performed with sonicates of heat killed Malassezia, and the intact uninfected skin of 10 patients with inactive psoriasis developed clinical and histological skin lesions similar to psoriasis (68). In addition, Elewski (69) reported a patient with psoriasis who developed active lesions in skin lesions of pityrosporum folliculitis. Several studies have demonstrated an improvement in scalp psoriasis following treatment with oral ketoconazole, combined with a decrease in the amount of yeast $(70,71)$. Taken together, these findings support the association between psoriasis and Malassezia spp. Previous studies on the prevalence of Malassezia spp. in patients with psoriasis identified several species, including $M$. globosa, M. furfur and M. sympodialis (72,73). Mechanistically, Malassezia spp. upregulates the expression of heat shock protein 70 , transforming growth factor- $\beta 1$ and integrin chains in keratinocytes, the expression of which is higher in psoriatic plaques colonized Malassezia plaques compared with noncolonized psoriatic plaques (74). However, further studies are required to determine whether Malassezia can induce the development of psoriatic lesions.

\section{Viruses}

$H I V$. HIV infection is an independent risk factor for 102,070 patients with psoriasis following elimination of age, sex and comorbidities (adjusted OR, 1.80; 95\% CI, 1.38-2.36) (75). Over $80 \%$ of HIV-positive patients with psoriasis have recurrent lesions when their $\mathrm{CD}^{+}{ }^{+}$lymphocyte count reaches $<450$. Furthermore, previous studies have reported that $\mathrm{CD}^{+}$counts $<200$ cells $/ \mathrm{mm}^{3}$ are associated with a 9-fold higher risk of clinically active psoriasis $(76,77)$. However, the association between $\mathrm{CD} 4^{+}$lymphocyte counts and psoriasis remains controversial. While $\mathrm{CD}^{+}$lymphocyte counts are very low in the terminal stages of HIV infection, psoriatic lesions may regress completely (78). The imbalance of the $\mathrm{CD} 4^{+} / \mathrm{CD}^{+}$lymphocyte ratio in patients with HIV may result in the disturbance of homeostasis, favouring psoriatic symptomatology (79). HLA-DR, which is rarely expressed in the epidermis of healthy individuals, plays an important role in antigen presentation. However, human keratinocytes can release interferon gamma (IFN $\gamma$ ) to induce HLA-DR expression (80). HIV infection increases HLA-DR expression in human keratinocytes by excessively secreting IFN $\gamma$, which results in the migration of leukocytes into skin tissues and promotes the reaction to streptococcal and staphylococcal superantigens, thus contributing to the psoriatic phenotype (81-83). Furthermore, certain viral proteins, including the negative regulatory factor protein and envelope glycoprotein GP120, function as superantigens in HIV infection, which increases the burden of psoriasis observed in patients with HIV $(84,85)$. In addition, psoriasis is more difficult to treat and recurs more frequently in HIV-infected individuals compared with noninfected individuals (86).

$H P V$. Jain et al (87) reported that genital warts (HPV infection) potentially trigger inverse psoriasis. However, these results may have been due to coincidence given that patients were lost to follow-up after the clearance of skin and genital lesions. Recently, a nationwide study performed over 12 years indicated that individuals with HPV have an approximately 2-fold increased risk of developing psoriasis compared with the general population. Furthermore, individuals with HPV infection have a higher risk of developing psoriasis with age compared with heathy individuals (88). However, the molecular mechanism by which HPV infection increases the incidence of psoriasis remains unclear. It has been speculated that the inflammatory state following HPV infection upregulates the synthesis of nerve growth factor (NGF), which influences the pathological features of psoriasis, such as keratinocyte proliferation, angiogenesis and T-cell activation. Notably, high NGF expression has been observed in psoriatic-prone skin compared with normal skin (89).

$H C V$. Imafuku and Nakayama (90) investigated the association between psoriasis and HCV infection. The results of this study demonstrated that $\mathrm{HCV}$ infection triggers psoriasis, particularly late-onset psoriasis, potentially due to upregulated expression of tumor necrosis factor- $\alpha$ (TNF- $\alpha$ ), a common mediator of the two conditions (91). Supporting this hypothesis, treatment of psoriasis with TNF- $\alpha$ antagonists, without deterioration of HCV, was reported. Farag et al (92) demonstrated that 90 patients with psoriasis who were infected with HCV had significantly increased PASI scores $(\mathrm{P}<0.001)$, suggesting that $\mathrm{HCV}$ infection may lead to the exacerbation of psoriasis. In addition, a positive association between the viral load and PASI scores was observed. The skin load, rather than the presence of $\mathrm{HCV}$ infection, may play a critical role in the pathogenesis of psoriasis. This cutaneous load is positively associated with the duration of disease (92). HCV infection not only increases psoriasis severity, but may also play a role in its different clinical aspects. Chun et al (93) recently confirmed the immunological association between HCV and psoriasis. It was demonstrated that patients with psoriasis who are $\mathrm{HCV}$-positive have increased expression levels of the inflammatory genes responsible for psoriasis development, including cathelicidin, Toll-like receptor 9 and IFN $\gamma$. However, the incidence of psoriasis and HCV substantially vary between race and nations. Further studies are required to investigate the association between psoriasis and $\mathrm{HCV}$ and determine the molecular mechanisms underlying the two conditions.

Human herpesvirus (HHV). Epstein-Barr virus (EBV) is a HVV that is carried by $90 \%$ of the population worldwide, and generally persists throughout an individual's lifetime, without causing disease (94). The results of a cross-sectional study demonstrated that neither severe psoriasis alone nor in combination with immunosuppressive therapy are associated with an increase in EBV or HHV6 replication in white blood cells (95). Loh et al (96) reported that a patient developed symptoms of glandular fever 3 weeks prior to the emergence of GP. In this case, serological evidence indicated a recent EBV infection and IgM positivity. Jiyad et al (97) reported that a 79-year-old woman presented with significant EBV viremia and generalized pustular psoriasis (GPP) and serial measurements of EBV DNA indicated an association with the deterioration of her clinical condition. The authors speculated that reactivation of EBV may have triggered the development of GPP. 
Furthermore, Yoneda et al (98) reported that two patients developed GPP after infection with cytomegalovirus (CMV). Increasing evidence suggests that CMV may be associated with GPP $(99,100)$. TNF- $\alpha$ expression has been observed in GPP lesions, where CMV DNA fragments were also detected in the same site (101). In addition, overexpression of CMV IE protein in keratinocytes is followed by an increase in TNF- $\alpha$ activity (102). TNF- $\alpha$, along with other cytokines, such as interferon-c (IFN-c) and IL-6, may be injurious, and the complex interaction of TNF- $\alpha$ in vivo potentially elicits the occurrence of GPP (103). However, Kirby et al (104) reported that CMV, HHV6 and HHV7 infections are unlikely to play important roles in the pathogenesis of psoriasis. In addition, limited studies have reported that infection with varicella-zoster virus and herpes simplex virus may be associated with the occurrence of psoriasis $(105,106)$. However, further studies are required to determine the molecular mechanism underlying the association between HHV infection and psoriasis (107).

\section{Other viruses}

Korzhova et al (108) reported that 25 patients with psoriasis presented antibodies to the Coxsackie B virus in diagnostic titres, with several patients having displayed a progressive increase in the titres of the aforementioned antibodies, which suggests an association between psoriasis and Coxsackie $B$ virus. In addition, antibodies to Coxsackie $B 1$ and $B 5$ viruses have been demonstrated to occur more frequently among seropositive patients, underscoring their particular importance in the development of psoriasis (108).

Chikungunya (CKG) infection, which is provoked by an RNA virus and transmitted by Aedes (A. aegypti and A. albopictus), is a re-emerging viral disease (109). CKG fever is perceived as an epidemic in Africa and Asia. CKG is characterized by a sudden fever with severe arthralgia, constitutional symptoms and skin eruption, which lasts for 1-7 days (110). It is also characterized by several cutaneous manifestations in axillae and perineal regions, including maculopapular eruption, centrofacial melanosis and aphthous-like ulcers (111). Inamadar et al (112) described two cases of an exacerbation of psoriasis following a suspected CKG infection. Furthermore, Seetharam and Sridevi (113) reported that five patients developed psoriasis 5-14 days after CKG infection, and two other patients experienced an exacerbation of existing psoriasis. The authors proposed that the virus acts as a superantigen and activates cellular immunity through innate or acquired pathways, thereby promoting immunological changes that produce different clinical manifestations in insusceptible individuals. Collectively, these findings suggest that CKG infection triggers psoriasis, particularly in endemic areas.

$Z i k a$ virus (ZIKV), an emerging arthropod-borne virus, belongs to the Flaviviridae family, and its epidemic scope is spreading throughout the tropical and subtropical regions of the world since the year of 2007 (114). Although ZIKV is mostly asymptomatic, the typical symptoms of infection consist of a mild fever, headache, fatigue, rash, arthritis and/or joint pain, myalgia and conjunctivitis $(115,116)$. To the best of our knowledge, Paniz Mondolfi et al (117) was the first to report a case of psoriasis that appeared 3 weeks after an uneventful regression of acute ZIKV infection. Based on the most recent experimental data on the biology of ZIKV infection in the skin, the authors hypothesized that ZIKV may have directly induced the development of GPP by stimulating keratinocyte-derived inflammatory mediator production and a multipotent T-cell driven immune reaction in the cutaneous milieu (118).

Human parvovirus B19 (PVB19), a single-stranded DNA virus, causes several clinical manifestations, including influenza-like illness, acute-onset polyarthropathy and rash (119). Several studies have reported the association between PVB19 infection and various chronic autoimmune and cutaneous diseases, including rheumatoid arthritis, systemic lupus erythematosus and multiple sclerosis $(120,121)$. Yazici et al (119) indicated a statistically significant association between PVB19 infection and psoriasis. Notably, 79\% patients with psoriasis presented specific anti-PVB19-IgG antibodies (119). Another study also supported the potential association between psoriasis and PVB19 infection, whereby PVB19 infection may induce the pathogenesis of psoriasis; however, the underlying molecular mechanism remains unclear (122). Future studies with larger sample sizes and measurements of immune parameters are required to determine the association between PVB19 infection and psoriasis.

In late December 2019, the world was introduced to the novel coronavirus disease (COVID-19). The novel SARS-CoV2, which humans encountered for the first time, binds ACE receptors to trigger pneumonia (123). Kutlu and Metin (124) reported a case of psoriasis exacerbation induced by treatment with hydroxychloroquine and oseltamivir in a patient with COVID-19. Although hydroxychloroquine may aggravate psoriasis, the presence of severe psoriasis within a short period may indicate that COVID-19 infection plays an important role in the pathogenesis of psoriasis $(125,126)$. Plasma concentrations of inflammation-related cytokines, including IL-2, IL-7 and IL-10, granulocyte colony-stimulating factor, interferon-induced protein 10 , monocyte chemokine 1 , macrophage inflammatory protein 1 and tumour necrosis factor, have recently been reported to be potentially associated with the exacerbation of psoriasis in patients infected with SARS-CoV2 (127).

\section{Other microorganisms}

Scabies, which is induced by a parasitic infection carried by the mite Sarcoptes scabiei, is a pruritic cutaneous disease, and several systemic diseases have been reported to be associated with scabies infection, such as chronic kidney disease and chronic obstructive pulmonary disease (128). Notably, scabies and psoriasis are both characterized by pruritic skin lesions $(129,130)$. In 1986, Keipert (131) reported that an individual with crusted scabies developed psoriasis. Liu et al (132) performed a nationwide study and demonstrated a potential association between scabies and psoriasis. Patients with scabies were reported to have an increased risk of psoriasis (hazard ratio, 3.03). A Th17 cell-mediated inflammatory pathway was speculated to function in patients with this condition. In addition, previous studies have reported elevated levels of IL-2, IL-4, IL-6, IL-17 and IFN-C in patients with both scabies and psoriasis. The risk of 
subsequent psoriasis may decrease with early and aggressive treatment of scabies (133-135).

\section{Conclusions}

Several microorganisms are associated with the onset or exacerbation of psoriasis. However, other predisposing factors, such as alcohol and drug consumption, should always be eliminated first. A better understanding of the pathogenesis of psoriasis induced by infection not only contributes to achieving a greater appreciation of the disease process but also provides guidance for treatment strategies. In some cases of infection, such as psoriasis associated with HHV, lesions may become resistant to treatment; thus, early identification and management may help avoid problems of nonadherence to some extent. The pathogenesis of infection-provoked psoriasis has not been precisely clarified. In most cases, the infection is proposed to function as a superantigen, stimulating the proliferation of $\mathrm{T}$-cells without prior intracellular processing by an antigen-presenting cell. Subsequently, infiltrating $\mathrm{T}$ cells induce psoriatic lesions. In some patients with a viral infection, the expression levels of cytokines increase, such as TNF- $\alpha$ and IFN $\gamma$, which is responsible for the development of psoriasis. However, anti-infective treatments are not always effective and require further investigation. In addition, further studies are required to determine why some individuals develop psoriasis following exposure to a specific infection.

\section{Acknowledgements}

Not applicable.

\section{Funding}

The present study was supported by the Zhejiang Provincial Natural Science Foundation of China (grant no. LY20H110002), the General Project Funds from the Health Department of Zhejiang Province (grant no. 2020KY446) and the outstanding Young People Fund in Zhejiang Provincial People's Hospital (grant no. ZRY2018C004 and ZRY2020C008).

\section{Availability of data and materials}

Not applicable.

\section{Authors' contributions}

YT, WX and YF conceived and designed the study. XT, NL, YY, YH and DX contributed to draft the manuscript and revised it critically for important intellectual content. WX and YF confirm the authenticity of all the raw data. All authors read and approved the final manuscript.

\section{Ethics approval and consent to participate}

Not applicable.

\section{Patient consent for publication}

Not applicable.

\section{Competing interests}

The authors declare that they have no competing interests.

\section{References}

1. Chandran V and Raychaudhuri SP: Geoepidemiology and environmental factors of psoriasis and psoriatic arthritis. J Autoimmun 34: J314-J321, 2010.

2. Munz OH, Sela S, Baker BS, Griffiths CE, Powles AV and Fry L: Evidence for the presence of bacteria in the blood of psoriasis patients. Arch Dermatol Res 302: 495-498, 2010.

3. Rademaker M, Agnew K, Anagnostou N, Andrews M, Armour K, Baker C, Foley P, Gebauer K, Gupta M, Marshman G, et al: Psoriasis and infection. A clinical practice narrative. Australas J Dermatol 60: 91-98, 2019.

4. Norrlind R: The significance of infections in the origination of psoriasis. Acta Rheumatol Scand 1: 135-144, 1955.

5. Mallon E, Bunce M, Savoie H, Rowe A, Newson R, Gotch F and Bunker CB: HLA-C and guttate psoriasis. Br J Dermatol 143: 1177-1182, 2015.

6. Gudjonsson JE, Thorarinsson AM, Sigurgeirsson B, Kristinsson KG and Valdimarsson H: Streptococcal throat infections and exacerbation of chronic plaque psoriasis: A prospective study. Br J Dermatol 149: 530-534, 2003.

7. Valdimarsson H, Thorleifsdottir RH, Sigurdardottir SL, Gudjonsson JE and Johnston A: Psoriasis-as an autoimmune disease caused by molecular mimicry. Trends Immunol 30: 494-501, 2009.

8. Sigurdardottir SL, Thorleifsdottir RH, Valdimarsson H and Johnston A: The association of sore throat and psoriasis might be explained by histologically distinctive tonsils and increased expression of skin-homing molecules by tonsil T cells. Clin Exp Immunol 174: 139-151, 2013.

9. Nardo AD, Vitiello A and Gallo RL: Cutting Edge: Mast cell antimicrobial activity is mediated by expression of cathelicidin antimicrobial peptide. J Immunol 170: 2274-2278, 2003.

10. Mabuchi $\mathrm{T}$ and Hirayama N: Binding affinity and interaction of LL-37 with HLA-C*06:02 in psoriasis. J Invest Dermatol 1901-1903, 2016

11. Qian L, Chen W, Sun W, Li M, Zheng R, Qian Q and Lv L: Antimicrobial peptide LL-37 along with peptidoglycan drive monocyte polarization toward CD14(high)CD16(+) subset and may play a crucial role in the pathogenesis of psoriasis guttata. Am J Transl Res 7: 1081-1094, 2015.

12. Langley RG and Ellis CN: Evaluating psoriasis with psoriasis area and severity index, psoriasis global assessment, and lattice system physician's global assessment. J Am Acad Dermatol 51: 563-569, 2004.

13. Fujisawa T, Murase K, Kanoh H, Takemura M, Ohnishi H and Seishima M: Adsorptive depletion of $\mathrm{CD}_{14}{ }^{+} \mathrm{CD} 16^{+}$proinflammatory monocyte phenotype in patients with generalized pustular psoriasis: Clinical efficacy and effects on cytokines. Ther Apher Dial 16: 436-444, 2012.

14. Hyder LA, Gonzalez J, Harden JL, Johnson-Huang LM, Zaba LC, Pierson KC, Eungdamrong NJ, Lentini T, Gulati N, Fuentes-Duculan J, et al: TREM-1 as a potential therapeutic target in psoriasis. J Invest Dermatol 133: 1742-1751, 2013.

15. Ruiz-Romeu E, Ferran M, Giménez-Arnau A, Bugara B, Lipert B, Jura J, Florencia EF, Prens EP, Celada A, Pujol RM and Santamaria-Babí LF: MCPIP1 RNase is aberrantly distributed in psoriatic epidermis and rapidly induced by IL-17A. J Invest Dermatol 136: 1599-1607, 2016.

16. Owen CM, Chalmers RJ, O'sullivan T and Griffiths CE: A systematic review of antistreptococcal interventions for guttate and chronic plaque psoriasis. Br J Dermatol 145: 886-890, 2001.

17. Owen CM, Chalmers R, O'Sullivan T and Griffiths CE: WITHDRAWN: Antistreptococcal interventions for guttate and chronic plaque psoriasis. Cochrane Database Syst Rev 3: CD001976, 2019.

18. Hone SW, Donnelly MJ, Powell F and Blayney AW: Clearance of recalcitrant psoriasis after tonsillectomy. Clin Otolaryngol Allied Sci 21: 546-547, 1996.

19. Thorleifsdottir RH, Sigurdardottir SL, Sigurgeirsson B, Olafsson JH, Sigurdsson MI, Petersen H, Arnadottir S, Gudjonsson JE, Johnston A and Valdimarsson H: Improvement of psoriasis after tonsillectomy is associated with a decrease in the frequency of circulating T cells that recognize streptococcal determinants and homologous skin determinants. J Immunol 188: 5160-5165, 2012. 
20. Thorleifsdottir RH, Sigurdardottir SL, Sigurgeirsson B Olafsson JH, Sigurdsson MI, Petersen H, Gudjonsson JE, Johnston A and Valdimarsson H: Patient-reported outcomes and clinical response in patients with moderate-to-severe plaque psoriasis treated with tonsillectomy: A randomized controlled trial. Acta Derm Venereol 97: 340-345, 2016.

21. Rachakonda TD, Dhillon JS, Florek AG and Armstrong AW: Effect of tonsillectomy on psoriasis: A systematic review. J Am Acad Dermatol 72: 261-275, 2015.

22. Garritsen FM, Kraag DE and De Graaf M: Guttate psoriasis triggered by perianal streptococcal infection. Clin Exp Dermatol 42: 536-538, 2017

23. Patrizi A, Costa AM, Fiorillo L and Neri I: Perianal streptococcal dermatitis associated with guttate psoriasis and/or balanoposthitis: A study of five cases. Pediatr Dermatol 11: 168-171, 1994.

24. Herbst RA, Hoch O, Kapp A and Weiss J: Guttate psoriasis trig gered by perianal streptococcal dermatitis in a four-year-old boy. J Am Acad Dermatol 42: 885-887, 2000.

25. Yamamoto Y, Hashimoto A, Togashi K, Takatsuka S and Ito M Effects of treatment for dental focal infection on pustulosis Palmaris et Plantaris. Jap J Dermatol 111: 821-826, 2001.

26. NG CY, Huang Y, Chu C, Wu T and Liu S: Risks for Staphylococcus aureus colonization in psoriasis patients: A systematic review and meta-analysis. Br J Dermatol 177: 967-977, 2017.

27. Kenny K, Reiser R, Bastida F and Norcross N: Production of enterotoxins and toxic shock syndrome toxin by bovine mammary isolates of Staphylococcus aureus. J Clin Microbiol 31: 706-707, 1993.

28. Tomi NS, Kränke B and Aberer E: Staphylococcal toxins in patients with psoriasis, atopic dermatitis, and erythroderma, and in healthy control subjects. J Am Acad Dermatol 53: 67-72, 2005

29. Göcmen JS, Sahiner N, Koçak M and Karahan ZC: PCR investigation of Panton-valentine leukocidin, enterotoxin, exfoliative toxin, and agr genes in Staphylococcus aureus strains isolated from psoriasis patients. Turk J Med Sci 45: 1345-1352, 2015.

30. Travers J, Hamid Q, Norris D, Kuhn C, Giorno RC, Schlievert PM, Farmer ER and Leung DY: Epidermal HLA-DR and the enhancement of cutaneous reactivity to superantigenic toxins in psoriasis J Clin Invest 104: 1181-1189, 1999.

31. Moriwaki Y, Takada K, Nagasaki T, Kubo N, Ishii T, Kose K, Kageyama T, Tsuji S, Kawashima K and Misawa $\mathrm{H}$ : IL-22/STAT3-induced increases in SLURP1 expression within psoriatic lesions exerts antimicrobial effects against Staphylococcus aureus. PLoS One 10: e140750, 2015.

32. Baker BS, Laman JD, Powles A, van der Fits L, Voerman JS Melief MJ and Fry L: Peptidoglycan and peptidoglycan-specific ThI cells in psoriatic skin lesions. J Pathol 209: 174-181, 2006.

33. Bianca B and Meyer TF: The human gastric pathogen Helicobacter pylori and its association with gastric cancer and ulcer disease. Ulcers 2011: 340157, 2011.

34. Pellicano R, Ribaldone DG, Fagoonee S, Astegiano M, Saracco GM and Mégraud F: A 2016 panorama of Helicobacter pylori infection: Key messages for clinicians. Panminerva Med 58: 304-137, 2016.

35. Al-Mendalawi M: Screening of Helicobacter pylori in patients with alopecia areata. Menoufia Med J 32: 748, 2019

36. Xingzhe Y: Relationship between Helicobacter pylori and rosacea: Review and discussion. BMC Infect Dis 18: 318, 2018.

37. Yu M, Zhang R, Ni P, Chen S and Duan G: Helicobacter pylori infection and psoriasis: A systematic review and meta-analysis. Medicina (Kaunas) 55: 645, 2019.

38. Testerman TL and Morris J: Beyond the stomach: An updated view of Helicobacter pylori pathogenesis, diagnosis, and treatment. World J Gastroenterol 20: 12781-12808, 2014

39. Kao CY, Sheu BS, Sheu SM, Yang HB, Chang WL, Cheng HC and Wu JJ: Higher motility enhances bacterial density and inflammatory response in dyspeptic patients infected with Helicobacter pylori. Helicobacter 17: 411-416, 2012.

40. Matysiak-Budnik T, Coffin B, Lavergne-Slove A, Sabate JM, Mégraud $\mathrm{F}$ and Heyman M: Helicobacter pylori increases the epithelial permeability to a food antigen in human gastric biopsies. Am J Gastroenterol 99: 225-232, 2004.

41. Wang SK, Zhu HF, He BS, Zhang ZY, Chen ZT, Wang ZZ and Wu GL: $\mathrm{CagA}^{+} H$ pylori infection is associated with polarization of $\mathrm{T}$ helper cell immune responses in gastric carcinogenesis. World J Gastroenterol 13: 2923-2931, 2007.

42. Magen E and Delgado JS: Helicobacter pylori and skin autoimmune diseases. World J Gastroenterol 20: 1510-1516, 2014.
43. Radić M: Role of Helicobacter pylori infection in autoimmune systemic rheumatic diseases. World J Gastroenterol 20: 12839-12846, 2014.

44. Zaromb A, Chamberlain D, Schoor R, Almas K and Blei F Periodontitis as a manifestation of chronic benign neutropenia. J Periodontol 77: 1921-1926, 2006.

45. Loos B: Systemic effects of periodontitis. Ann R Australas Coll Dent Surg 18: 27-29, 2006.

46. El-Shinnawi U and Soory M: Associations between periodontitis and systemic inflammatory diseases: Response to treatment. Recent Pat Endocr Metab Immune Drug Discov 7: 169-188, 2013

47. Bunte K and Beikler T: Th17 Cells and the IL-23/IL-17 Axis in the pathogenesis of periodontitis and immune-mediated inflammatory diseases. Int J Mol Sci 20: 3394, 2019.

48. Hirschfeld J, Higham J, Chatzistavrianou D, Blair F, Richards A and Chapple ILC: Systemic disease or periodontal disease? Distinguishing causes of gingival inflammation: A guide for dental practitioners. Part 2: Cancer related, infective, and other causes of gingival pathology. Br Dent J 227: 1029-1034, 2019.

49. Leech M and Bartold PM: The association between rheumatoid arthritis and periodontitis. Best Pract Res Clin Rheumatol 29: 189-201, 2015.

50. Ungprasert $\mathrm{P}$, Wijarnpreecha $\mathrm{K}$ and Wetter DA: Periodontitis and risk of psoriasis: A systematic review and meta-analysis. J Eur Acad Dermatol Venereol 31: 857-862, 2017.

51. Abdullah SN, Farmer EA, Spargo L, Logan R and Gully N: Porphyromonas gingivalis peptidylarginine deiminase substrate specificity. Anaerobe 23: 102-108, 2013

52. Jenning M, Marklein B, Ytterberg J, Zubarev RA, Joshua V, van Schaardenburg D, van de Stadt L, Catrina AI, Nonhoff U, Häupl T, et al: Bacterial citrullinated epitopes generated by Porphyromonas gingivalis infection-a missing link for ACPA production. Ann Rheum Dis 79: 1194-1202, 2020.

53. Takahashi $\mathrm{T}$ and Yamasaki K: Psoriasis and Antimicrobial Peptides. Int J Mol Sci 21: 6791, 2020.

54. Sharma A, Raman A and Pradeep AR: Association of chronic periodontitis and psoriasis: Periodontal status with severity of psoriasis. Oral Dis 21: 314-319, 2015

55. Zhang X, Gu H, Xie S and Su Y: Periodontitis in patients with psoriasis: A systematic review and meta-analysis. Oral Dis: Aug 27, 2020 (Epub ahead of print). doi: 10.1111/odi.13617.

56. Monson C: Periodontal aspects for psoriasis: A systematic review. J Clin Res Dermatol 3: 1-8, 2016.

57. Skudutyte-Rysstad R, Slevolden EM, Hansen BF, Sandvik L and Preus HR: Association between moderate to severe psoriasis and periodontitis in a Scandinavian population. BMC Oral Health 14: 139, 2014.

58. Birkelund S, Johnsen $\mathrm{H}$ and Christiansen G: Chlamydia trachomatis serovar L2 induces protein tyrosine phosphorylation during uptake by HeLa cells. Infect Immun 62: 4900-4908, 1994.

59. Ferreri AJ, Dolcetti R, Dognini GP, Malabarba L, Vicari N, Pasini E, Ponzoni M, Cangi MG, Pecciarini L, Resti AG, et al: Chlamydophila psittaciis viable and infectious in the conjunctiva and peripheral blood of patients with ocular adnexal lymphoma: Results of a single-center prospective case-control study. Int J Cancer 123: 1089-1093, 2008.

60. Ferreri AJ, Dolcetti R, Magnino S, Doglioni C and Ponzoni M: Chlamydial infection: The link with ocular adnexal lymphomas. Nat Rev Clin Oncol 6: 658-669, 2009.

61. Fabris M, De Vita S, Pasini E, Quartuccio L, Pontarini E, Lombardi S, Fabro C, Sarzi-Puttini P, Pellerito R, Benucci M, et al: Chlamydophila psittaci subclinical infection in chronic polyarthritis. Clin Exp Rheumatol 29: 977-982, 2011.

62. Stinco G, Fabris M, Pasini E, Pontarini E, Patriarca MM, Piccirillo F, De Vita S and Dolcetti R: Detection of DNA of Chlamydophila psittaci in subjects with psoriasis: A casual or a causal link? Br J Dermatol 167: 926-928, 2012.

63. Rockey DD, Lenart J and Stephens RS: Genome sequencing and our understanding of chlamydiae. Infect Immun 68: 5473-5479, 2000.

64. Javad G, Taheri Sarvtin M,Hedayati MT, Hajheydari Z, Yazdani J and Shokohi T: Evaluation of Candida colonization and specific humoral responses against Candida albicans in patients with atopic dermatitis. Biomed Res Int 2015: 849206, 2015.

65. Rademaker M, Agnew K, Anagnostou N, Andrews M, Armour K, Baker C, Foley P, Gebauer K, Gupta M, Marshman G, et al: Psoriasis and infection. A clinical practice narrative. Australas J Dermatol 2: 91-98, 2018. 
66. Aşçioğlu Ö, Soyuer Ü and Aktaş E: Improvement of psoriasis with oral nystatin. In: Candida and Candidamycosis. Federation of European Microbiological Societies Symposium Series, vol 50. Tümbay E, Seeliger HPR and Anğ Ö (eds). Springer, Boston, MA pp279-281, 1991.

67. Fry L, Baker BS, Powles AV, Fahlen A and Engstrand L: Is chronic plaque psoriasis triggered by microbiota in the skin? Br J Dermatol 169: 47-52, 2013

68. Lober CW, Belew PW, Rosenberg EW and Bale G: Patch tests with killed sonicated microflora in patients with psoriasis. Arch Dermatol 5: 322-325, 1982.

69. Elewski B: Does Pityrosporum ovale have a role in psoriasis? Arch Dermatol 126: 1111-1112, 1990.

70. Farr PM, Krause LB, Marks JM and Shuster S: Response of scalp psoriasis to oral ketoconazole. Lancet 326: 921-922, 1985.

71. Rosenberg EW and Belew PW: Improvement of psoriasis of the scalp with ketoconazole. Arch Dermatol 118: 370-371, 1982.

72. Rudramurthy SM, Honnavar P, Chakrabarti A, Dogra S, Singh P and Handa S: Association of Malassezia species with psoriatic lesions. Mycoses 57: 483-838, 2014.

73. Gomez-Moyano E, Crespo-Erchiga V, Martínez-Pilar L, Godoy Diaz D, Martínez-García S, Lova Navarro M and Vera Casaño A: Do Malassezia species play a role in exacerbation of scalp psoriasis? J Mycol Med 24: 87-92, 2014.

74. Baroni A, Paoletti I, Ruocco E, Agozzino M, Tufano MA and Donnarumma G: Possible role of Malassezia furfur in psoriasis: Modulation of TGF-beta1, integrin, and HSP70 expression in human keratinocytes and in the skin of psoriasis-affected patients. J Cutan Pathol 31: 35-42, 2004.

75. Yen YF, Jen IA, Chen M, Lan YC, Lee CY, Chuang PH, Lee Y and Arthur Chen YM: HIV Infection increases the risk of incident psoriasis: A nationwide population-based cohort study in Taiwan. J Acquir Immune Defic Syndr 75: 493-499, 2017.

76. Goh BK, Chan RK, Sen P, Theng CT, Tan HH, Wu YJ and Paton NI: Spectrum of skin disorders in human immunodeficiency virus-infected patients in Singapore and the relationship to CD4 lymphocyte counts. Int J Dermatol 46: 695-699, 2007.

77. Alpalhão M, Borges-Costa $J$ and Filipe P: Psoriasis in HIV infection: An update. Int J STD AIDS 6: 596-604, 2019.

78. Colebunders R, Blot K, Mertens V and Dockx P: Psoriasis regression in terminal AIDS. Lancet 339: 1110, 1992.

79. Roederer M, Dubs JG, Anderson MT, Raju PA, Herzenberg LA and Herzenberg LA: CD8 naive T cell counts decrease progressively in HIV-infected adults. J Clin Invest 95: 2061-2066, 1995.

80. Kim YH and Kim JW: The effect of calcium on HLA-DR synthesis of cultured keratinocytes induced by interferon-gamma. J Dermatol Sci 1: 382, 1990.

81. Baker BS, Powles AV, Valdimarsson H and Fry L: An altered response by psoriatic keratinocytes to gamma interferon. Scand J Immunol 28: 735-740, 2006.

82. Terui T, Aiba S, Kato T, Tanaka T and Tagami H: HLA-DR antigen expression on keratinocytes in highly inflamed parts of psoriatic lesions. Br J Dermatol 116: 87-93, 1987.

83. Auböck J, Romani N, Grubauer G and Fritsch P: HLA-DR expression on keratinocytes is a common feature of diseased skin. Br J Dermatol 114: 465-472, 1986.

84. Townsley-Fuchs J, Neshat MS, Margolin DH, Braun J and Goodglick L: HIV-1gp120: A novel viral B cell superantigen. Int Rev Immunol 14: 325-338, 1997.

85. Torres BA and Johnson HM: Identification of an HIV-1 Nef peptide that binds to HLA class II antigens. Biochem Biophys Res Commun 200: 1065-1065, 1994.

86. Fernandes S, Pinto GM and Cardoso J: Particular clinical presentations of psoriasis in HIV patients. Int J STD AIDS 22: 653-654 2011.

87. Jain SP, Gulhane S, Pandey N and Bisne E: Human papilloma virus infection and psoriasis: Did human papilloma virus infection trigger psoriasis? Indian J Sex Transm Dis AIDS 36: 201-203, 2015

88. Chen ML, Kao WM, Huang JY, Hung YM and Wei CC: Human papillomavirus infection associated with increased risk of new-onset psoriasis: A nationwide population-based cohort study. Int J Epidemiol 49: 786-797, 2020.

89. Raychaudhuri SP, Jiang WY and Raychaudhuri SK: Revisiting the Koebner phenomenon: Role of NGF and its receptor system in the pathogenesis of psoriasis. Am J Pathol 172: 961-971, 2008

90. Imafuku S and Nakayama J: Profile of patients with psoriasis associated with hepatitis C virus infection. J Dermatol 40: $428-433,2013$
91. Di Nuzzo S, Boccaletti V, Fantini C, Cortelazzi C, Missale G, Fabrizi G, Lotti T, Hercogová J and Pagliarello C: Are Anti-TNF- $\alpha$ agents safe for treating psoriasis in Hepatitis C virus patients with advanced liver disease? Case reports and review of the literature. Dermatology 232: 102-106, 2015.

92.Farag AGA, Elshayb EE, Sharaky DRA, Elashafey EN and Khadra AAEA: Role of HCV infection in psoriasis: A clinical and immunohistochemical study. J Clin Diagnostic Res 13: WC01-WC06, 2019. doi: 10.7860/JCDR/2019/39627.12833.

93. Chun K, Afshar M, Audish D, Kabigting F, Paik A, Gallo R and Hata T: Hepatitis $\mathrm{C}$ may enhance key amplifiers of psoriasis. J Eur Acad Dermatol Venereol 4: 672-678, 2016.

94. Young LS and Rickinson AB: Epstein-Barr virus: 40 years on. Nat Rev Cancer 4: 757-768, 2004.

95. Neimann AL, Hodinka RL, Joshi YB, Elkan M and Gelfand JM: Epstein-Barr virus and human herpesvirus type 6 infection in patients with psoriasis. Eur J Dermatol 16: 548-552, 2006.

96. Loh E, Fung MA and Maverakis E: Acute Guttate psoriasis in a 15-year-old girl with Epstein-Barr virus infection. Arch Dermatol 148: 658-659, 2012.

97. Jiyad Z, Moriarty B, Creamer D and Higgins E: Generalized pustular psoriasis associated with Epstein-Barr virus. Clin Exp Dermatol 40: 164-168, 2015.

98. Yoneda K, Matsuoka-Shirahige Y, Demitsu T and Kubota Y: Pustular psoriasis precipitated by cytomegalovirus infection. $\mathrm{Br}$ J Dermatol 167: 1186-1189, 2012.

99. Ali FR, Green R, McMullen E, Motta L and Judge MR: Cutaneous cytomegalovirus complicating pustular psoriasis. $\mathrm{Br}$ J Dermatol 71: 670-671, 2014

100. Yoneda K, Matsuoka-Shirahige Y, Demitsu T and Kubota Y: Cytomegalovirus infection is one of the precipitating factors for pustular psoriasis. J Dermatol Sci 69: E38, 2013.

101. Smith PD, Saini SS, Raffeld M, Manischewitz JF and Wahl SM: Cytomegalovirus induction of tumor necrosis factor-alpha by human monocytes and mucosal macrophages. J Clin Invest 90 1642-1648, 1992.

102. Marzouk S, S R, I S, N Z, Abdel Hay R and M S: Role of cytomegalovirus infection and tumor necrosis factor- $\alpha$ in psoriasis J Egypt Wom Dermatol Soc: 34-39, 2009.

103. Arican O, Aral M, Sasmaz S and Ciragil P: Serum levels of TNF-alpha, IFN-gamma, IL-6, IL-8, IL-12, IL-17, and IL-18 in patients with active psoriasis and correlation with disease severity. Mediators Inflamm 2005: 273-279, 2005.

104. Kirby B, Al-Jiffri O, Cooper RJ, Corbitt G, Klapper PE and Griffiths CE: Investigation of cytomegalovirus and human herpes viruses 6 and 7 as possible causative antigens in psoriasis. Acta Derm Venereol 80: 404-406, 2000.

105. Ito T and Furukawa F: Psoriasis guttate acuta triggered by varicella zoster virus infection. Eur J Dermatol 10: 226-227, 2000.

106. Zampetti A, Gnarra M, Linder D, Digiuseppe MD, Carrino N and Feliciani C: Psoriatic pseudobalanitis circinata as a post-viral koebner phenomenon. Case Rep Dermatol 2: 183-188, 2010.

107. Weitz M, Kiessling C, Friedrich M, Prösch S, Höflich C, Kern F, Volk HD, Sterry W, Asadullah K and Döcke WD: Persistent CMV infection correlates with disease activity and dominates the phenotype of peripheral $\mathrm{CD} 8^{+} \mathrm{T}$ cells in psoriasis. Exp Dermatol 20: 561-567, 2011.

108. Korzhova TP, Shyrobokov VP, Koliadenko VH Korniushenko OM, Akhramieieva NV and Stepanenko VI: Coxsackie B viral infection in the etiology and clinical pathogenesis of psoriasis. Likarska Sprava: 54-58, 2001 (In Ukrainian).

109. Cabié A, Ledrans M and Abel S: Chikungunya virus infections. N Engl J Med 373: 94, 2015.

110. Sasaki Y, Manda S, Sato T, Maeda T, Miyazaki T, Nakanishi K and Urita Y: Chikungunya virus infection presenting with persistent arthralgia without fever. J Gen Family Med 16: 204-207, 2015

111. Riyaz N, Riyaz A, Rahima, Abdul Latheef EN, Anitha PM, Aravindan KP, Nair AS and Shameera P: Cutaneous manifestations of chikungunya during a recent epidemic in Calicut, north Kerala, south India. Indian J Dermatol Venereol Leprol 76 671-676, 2010

112. Inamadar AC, Palit A, Sampagavi VV, Raghunath S and Deshmukh NS: Cutaneous manifestations of chikungunya fever: Observations made during a recent outbreak in south India. Int J Dermatol 47: 154-159, 2008.

113. Seetharam KA and Sridevi K: Chikungunya infection: A new trigger for psoriasis. J Dermatol 10: 1033-1034, 2011. 
114. Álvaro F, Juan C and Pilar M: Emergence and spreading potential of Zika virus. Front Microbiol 7: 1667, 2016.

115. Musso D and Gubler DJ: Zika virus. Clin Microbiol Rev 29: 487, 2016.

116. Paniz-Mondolfi AE, Rodriguez-Morales AJ, Blohm G, Marquez $M$ and Villamil-Gomez WE: ChikDenMaZika Syndrome: The challenge of diagnosing arboviral infections in the midst of concurrent epidemics. Ann Clin Microbiol Antimicrob 15: 42, 2016.

117. Paniz Mondolfi AE, Hernandez Perez M, Blohm G, Marquez M, Mogollon Mendoza A, Hernandez-Pereira CE, Escalona MA, Lodeiro Colatosti A, Rothe DeArocha J and Rodriguez Morales AJ: Generalized pustular psoriasis triggered by Zika virus infection. Clin Exp Dermatol 2: 171-174, 2017.

118. Tappe D, Pérez-Girón JV, Zammarchi L, Rissland J, Ferreira DF, Jaenisch T, Gómez-Medina S, Günther S, Bartoloni A, Muñoz-Fontela $\mathrm{C}$ and Schmidt-Chanasit J: Cytokine kinetics of Zika virus-infected patients from acute to reconvalescent phase. Med Microbiol Immun 205: 269-273, 2016.

119. Yazici AC, Aslan G, Baz K, Ikizoglu G, Api H, Serin MS Tezcan S, Emekdas G and Tasdelen B: A high prevalence of parvovirus B19 DNA in patients with psoriasis. Arch Dermatol Res 298: 231-235, 2006.

120. Nakashima I, Fujihara K and Itoyama Y: Human parvovirus B19 infection in multiple sclerosis. Eur Neurol 42: 36-40, 1999

121. Page C, François C, Goëb V and Duverlie G: Human parvovirus B19 and autoimmune diseases. Review of the literature and pathophysiological hypotheses. J Clin Virol 72: 69-74, 2015.

122. Mehmet Y, Ceyhan AM, Arıdoğan BC, Koç İG and Selçuk K: Investigation of relationship between parvovirus B19 infection and psoriasis. Turkderm 44: 49-50, 2010.

123. Fu Y, Cheng Y and Wu Y: Understanding SARS-CoV-2-mediated inflammatory responses: From mechanisms to potential therapeutic tools. Virol Sin 35: 266-271, 2020.

124. Kutlu Ö and Metin A: A case of exacerbation of psoriasis after oseltamivir and hydroxychloroquine in a patient with COVID-19: Will cases of psoriasis increase after COVID-19 pandemic? Dermatol Ther 33: e13383, 2020.
125. Vine JE, Hymes SR, Warner NB and Cohen PR: Pustular psoriasis induced by hydroxychloroquine: A case report and review of the literature. J Dermatol 23: 357-361, 1996.

126. Gray RG: Hydroxychloroquine provocation of psoriasis. J Rheumatol 12: 391, 1985.

127. Huang C, Wang Y, Li X, Ren L, Zhao J, Hu Y, Zhang L, Fan G, $\mathrm{Xu} \mathrm{J}, \mathrm{Gu} \mathrm{X}$, et al: Clinical features of patients infected with 2019 novel coronavirus in Wuhan, China. Lancet 395: 497-506, 2020.

128. Chung SD, Wang KH, Huang CC and Lin HC: Scabies increased the risk of chronic kidney disease: A 5-year follow-up study. J Eur Acad Dermatol Venereol 28: 286-292, 2014.

129. He R, Gu X,LaiW,Peng Xand Yang G:Transcriptome-microRNA analysis of Sarcoptes scabiei and host immune response. PLoS One 12: e177733, 2017.

130. Arlian LG and Morgan MS: A review of Sarcoptes scabiei: Past, present and future. Parasite Vector 10: 297, 2017.

131. Keipert JA: Norwegian scabies in a girl with psoriasis. Australas J Dermatol 27: 29-32, 1986.

132. Liu JM, Lin CY, Chang FW, Liu YP, Liang CP and Hsu RJ: Increased risk of psoriasis following scabies infection: A nationwide population-based matched-cohort study. J Dermatol 3: 302-308, 2018

133. Abd El-Aal AA, Hassan MA, Gawdat HI, Ali MA and Barakat M: Immunomodulatory impression of anti and pro-inflammatory cytokines in relation to humoral immunity in human scabies. Int J Immunopathol Pharmacol 29: 188-194, 2016.

134. Liu X, Walton SF, Murray HC, King M, Kelly A, Holt DC, Currie BJ, McCarthy JS and Mounsey KE: Crusted scabies is associated with increased IL-17 secretion by skin T cells. Parasite Immunol 36: 594-604, 2014.

135. Mounsey KE, Murray HC, Bielefeldt-Ohmann H, Pasay C, Holt DC, Currie BJ, Walton SF and McCarthy JS: Prospective study in a porcine model of Sarcoptes scabiei indicates the association of Th2 and Th17 pathways with the clinical severity of scabies. PLoS Negl Trop Dis 9: e3498, 2015. 